\title{
Desumanização da população negra: genocídio como princípio tácito do capitalismo
}

\author{
Dehumanization of the black population: \\ genocide as tacit principle of capitalism
}

Magali da Silva Almeida*

\begin{abstract}
Resumo - Este artigo apresenta algumas reflexões acerca do genocídio da população negra, expressão da violência racial institucionalizada no Brasil. Privilegiou-se a análise de indicadores sociorraciais para compreender a desigualdade racial na Diáspora Negra e perceber que a experiência da população negra é marcada por múltiplos e contraditórios processos antinegros. Os estudos críticos e contemporâneos da Diáspora são os fundamentos para uma interpretação do racismo antinegro. As raízes deste remontam à emergência do Estado moderno e colonial, e suas ideologias e práticas discriminatórias reconfiguradas ao longo do desenvolvimento do capitalismo. O estudo adota o conceito de Diáspora Negra como genocídio, mas abre as possibilidades de múltiplas resistências e lutas pela materialização e emancipação humana.
\end{abstract}

Palavras chave: raça; genocídio; terror racial; resistências; emancipação humana.

\begin{abstract}
This paper presents some reflections about the genocide of the black population, expression of institutionalized racial violence in Brazil. We focused on the analysis of socio-racial indicators for understanding racial inequality in the African Diaspora and the experience of the black population is characterized by multiple and contradictory anti-black processes. The critical and contemporary studies of the Diaspora are the basis for an interpretation of anti-black racism. The roots for this go back to the emergence of the modern colonial state and its ideologies and discriminatory practices reconfigured along capitalist development. The study adopts the concept of African Diaspora as genocide, but opens up the possibilities of multiple resistances and struggles for human emancipation and materialization. Keywords: race; genocide; racial terror; resistances; human emancipation
\end{abstract}

\footnotetext{
* Doutora em Serviço Social. Professora da Universidade Federal da Bahia (Ufba). Pesquisadora sobre Relações Étnico-Raciais e de Gênero da Ufba/Proafro/Uerj. Representante do Cfess na Comissão Interssetorial de Saúde da População Negra (CISPN) do Ministério da Saúde (MS). Correspondência: Instituto de Psicologia: Rua Aristides Novis, 197, Federação. CEP: 40.210-630, Salvador-BA. E-mail: <quilombola_rio@yahoo.com.br>.
} 


\title{
Introdução
}

\begin{abstract}
Não lavarei minha mão/ Com água doce ou salgada./ Tenho as mãos para outras coisas,/ Não as desejo lavadas./ Minhas mãos podem estar sujas/ De terra, barro e azeite:/ São vestígios das ações/ Num mundo de boca amarga./ Não sou Pilatos./ Prefiro Errar, porém do meu erro/ Mostrar que penso na ação./ As mãos são fios nervosos,/ Condutos do coração./ São antenas dirigidas/ Ao sol que brilha no céu./ As mãos sujas e calosas/ Mancham juntas, são milhões./ Milhões de mãos que desejam/ Se irmanam ao coração./ Não lavarei minhas mãos em bacia de platina:/ Quero-as sujas, mas presentes/ Na hora que se aproxima. (CLOVIS MOURA, 1977).
\end{abstract}

Durante minha trajetória de vida, tenho experimentado a "sensação" de estar começando sempre do zero. Refiro-me à luta histórica, mais singular, de milhões de trabalhadoras e trabalhadores negros e brasileiros pelo reconhecimento de suas necessidades humanas, se é que o capitalismo nos permite esta possibilidade. Estamos (implico-me nesse contexto) sempre sobressaltadas(os) diante da violência estrutural perpetrada contra nós, desde o nascimento, com a qual convivemos durante toda vida. O racismo tem apartado do acesso aos direitos humanos, em todo planeta, multidões de africanos e seus descendentes, dentro e fora da África.

No Brasil, resistimos cotidianamente à morte anunciada pela discriminação racial. No entanto, na maioria das vezes rendemo-nos diante da força da mídia que, maciçamente, naturaliza a violência racial contra a população negra em seus programas sensacionalistas, ridicularizando e inferiorizando a imagem desse grupo étnico-racial no trabalho, na educação, na religiosidade, no noticiário policial e até no exercício da sexualidade e orientação sexual. A mídia é apenas um dentre os muitos dispositivos de poder hegemônicos.

O pano de fundo que se movimenta e se transmuta historicamente são as ideologias raciais que estruturam as relações sociais no Brasil, sobre as quais se reafirmam os preconceitos e as práticas discriminatórias que dão materialidade ao racismo "à brasileira". Este racismo, cuja existência material é reconhecida pela população, dialeticamente nega a existência dos agentes, pois, no Brasil, "ninguém é racista". Desconhecidos esses agentes, nutre-se a impunidade, a invisibilidade, o silêncio e, consequentemente, maiores são as dificuldades para seu enfrentamento através de políticas públicas.

Prevalecem, no Brasil, de maneira densa, as ideias de mestiçagem e democracia racial, em contraposição às ideias de identidade negra forjada pelos movimentos negros, cujos projetos em disputa têm permeado as arenas de luta no campo social e político. Neste cenário, algumas conquistas dos movimentos negros são garantidas através da implantação de políticas de ações afirmativas para a população negra na educação (educação básica, ensino fundamental, médio e superior), no mercado de trabalho, na política de saúde etc., em consonância aos preceitos constitucionais e dentro dos limites jurídicos normativos do Estado de Direito. Longe da garantia de 


\section{ReVistg all paUtg}

\} DESUMANIZAÇÃO DA POPULAÇÃO NEGRA - ALMEIRA, M. S. \}

atendimento às suas necessidades mínimas, a população negra é o segmento populacional que ocupa, maciçamente, a base da pirâmide social, e sua presença no topo é quase inexistente.

Como afirma Ricardo Henriques (2001, p.9), a pobreza e a indigência no Brasil não agem democraticamente, pois não atingem igualmente os distintos grupos raciais pertencentes ao contingente de 53 milhões de pobres e 22 milhões de indigentes.

Os negros em 1999 representam 45\% da população brasileira, mas correspondem a $64 \%$ da população pobre e $69 \%$ da população indigente. Os brancos, por sua vez, são $54 \%$ da população total, mas somente $36 \%$ dos pobres e $31 \%$ dos indigentes. Ocorre que, dos $53 \mathrm{mi}-$ Ihões de brasileiros pobres, 19 milhões são brancos, 30,1 milhões pardos e 3,6 milhões, pretos. Entre os 22 milhões de indigentes temos 6,8 milhões brancos, 13,6 milhões pardos e 1,5 milhão, pretos.

Este artigo apresenta algumas reflexões sobre a desumanização da população negra e sua experiência na Diáspora Negra como expressão da violência racial institucionalizada no Brasil, fazendo parte de um amplo processo de dominação/opressão capitalista na consolidação dos Estadosnação e do colonialismo.

Privilegiei, primeiramente, a apresentação de alguns indicadores sociais para demonstrar o racismo como fator relevante para as desigualdades sociais, bem como o modo como ele opera na produção das iniquidades, entre negros e brancos, no acesso ao conjunto dos direitos.

Em seguida, retomo alguns estudos críticos sobre a Diáspora Negra, cuja noção é concebida, neste estudo, como marcada por múltiplos e contraditórios processos genocidas antinegros (VARGAS, 2010). A experiência comum de abusos perpetrados por processos antinegros na Diáspora Negra, sobretudo nos países em desenvolvimento, não é somente dominante, mas inerente ao sistema capitalista em sua fase contemporânea e ao Estado-nação imperial (VARGAS, 2010).

A Diáspora Negra, enquanto um conceito histórico é, por essência, dinâmico e ao mesmo tempo político. Assim, enfoca o terror racial como uma de suas dimensões e possui o genocídio antinegro como sua característica fundamental. Nestes termos, que desafios são colocados como saída para os negros da Diáspora Negra?

\section{Indicadores sociais ou expressões do genocídio antinegro? A realidade que não quer calar}

Os estudos estatísticos têm constatado que há um fosso entre a população negra e a população branca, em termos de acesso e oportunidades. A ausência de negros nas profissões de prestígio, na política, em 


\section{hevista pll paעtg}

\} DESUMANIZAÇÃO DA POPULAÇÃO NEGRA - ALMEIRA, M. S. \}

algumas expressões artísticas, na mídia etc., é resultado de uma longa história de exclusão, na qual o racismo e o sexismo atuam definindo para homens e mulheres negras lugares desprivilegiados na sociedade, quase intransponíveis. É preciso que falemos do nosso lugar, a partir de nossa perspectiva e crença.

Gonzalez (1984) afirma que devemos romper com a domesticação, confirmando nossa fala justamente pelo motivo de sempre termos sido tratados como objetos e infantilizados (infans é aquele que não tem fala própria; é a criança que fala sobre si em terceira pessoa, porque é falada pelos adultos).

Beatriz Nascimento, intelectual dotada de qualidades ímpares, teve a sua obra revisitada por Ratts (2007). Sua produção nutre a nossa memória de informações históricas imprescindíveis para vermos o Brasil sob outro ângulo. Obra essa que libertou a negritude do aprisionamento acadêmico do passado escravista ao cunhar o conceito de quilombo urbano, "conceito com o qual ela ressignifica o território/favela como espaço de continuidade de uma experiência histórica que sobrepõe a escravidão à marginalização social, à segregação e à resistência dos negros no Brasil." (RATTS, 2007, p. 11).

As reflexões trazidas à baila por Lelia Gonzalez (1984) e Beatriz Nascimento apud Ratts (2007) retratam a violência do racismo e do sexismo a que historicamente é submetida a população negra em geral e, em particular, as mulheres negras. Tal fato demonstra como o mito da democracia racial brasileira encobriu os efeitos do racismo, retificando-o e criando a possibilidade da reprodução das desigualdades entre os grupos raciais no Brasil. Contudo, isso também mostrou toda competência teórica e política com que as mulheres negras brasileiras formularam análises da realidade, demonstrando sua capacidade de reagir ao "lugar" social imposto pela classe dominante.

Esse preâmbulo serve para atualizar o reconhecido papel das muIheres negras guerreiras no cenário da luta contra o racismo e o sexismo nos anos de 1970. Ressalto a importância dos estudos quantitativos escritos por Hasenbalg e Silva(1979) e Hasenbalg (1988), que indubitavelmente só puderam ser materializados devido à contribuição crítica do Movimento Negro brasileiro ao mito da democracia racial.

Essa pressão exercida pelos movimentos sociais, naquela ocasião, fez com que a academia voltasse seu olhar para o racismo. Se os estudos sobre indicadores ganham o cenário acadêmico, afirmando o caráter estrutural da raça na produção da desigualdade, é inegável a contribuição de Lélia Gonzalez (1984), Beatriz Nascimento apud Ratts 2007 (e outros militantes na democratização e no enegrecimento da academia brasileira.

Inicio minha reflexão concordando com o professor e pesquisador da Universidade Federal do Rio de Janeiro (UFRJ), Dr. Marcelo Paixão (PAIXÃO, 2003; PAIXÃO et al, 2010). Estamos de acordo quanto ao fato 


\section{ReVistg all paUtg}

\} DESUMANIZAÇÃO DA POPULAÇÃO NEGRA - ALMEIRA, M. S. \}

de que o aumento das demandas dos negros, no Brasil, resulta das infinitas denúncias de racismo e as proposições para seu combate, realizadas pelos movimentos negros. Resultam, também, da ampliação de pesquisas e estudos dedicados a mostrar, empiricamente, os fundamentos raciais de nosso quadro de desigualdades sociais.

$\mathrm{Na}$ Academia, a desconstrução da ideia de que, no Brasil, as relações raciais são democráticas, definida corretamente como mito, foi realizada nos anos 1950 por Florestan Fernandes e outros pesquisadores da Universidade de São Paulo (USP). Ainda assim, foram as contribuições de Carlos Hasenbalg (1979), e de Carlos Hasenbalg e Nelson do Vale Silva (1988) que efetivamente abriram um novo momento, marcado pelo uso sistemático de estatísticas e indicadores.

Deste modo, a realidade das desigualdades raciais brasileiras passou a ser vista de forma mais objetiva, favorecendo uma ampliação do grau de legitimidade do movimento negro; concomitantemente, tornando incompreensíveis os motivos pelo quais os afro-descendentes passam um século à margem de quaisquer políticas ativas de integração social, por parte do Estado e, o que é pior, com anuência da quase totalidade das organizações da sociedade civil brasileira. (PAIX ̃̂O, 2003, p. 11-12).

\section{Mercado de trabalho}

Marcelo Paixão (2003) parte do pressuposto de que os constrangimentos externos sofridos pela economia brasileira, o modelo econômico adotado e a subordinação do país às diretrizes dos bancos multilaterais e dos credores externos, produziram um aprofundamento da crise social. Percebe-se que, embora o autor tenha buscado trabalhar com vários indicadores sociais, ele se deteve no estudo do negro no mercado de trabalho. Concluiu, então, que a qualidade da inserção dos negros no mercado de trabalho brasileiro é substancialmente inferior à da população branca.

Segundo Paixão (2003, p.108-109), nas seis regiões metropolitanas cobertas pela Pesquisa de Emprego e Desemprego (PED), em 1998 os negros encontravam-se com maior frequência nos ramos e setores tradicionais da economia, trabalhando em ocupações manuais e de menor prestígio social. Eles estavam mais representados na População Economicamente Ativa (PEA) das regiões menos desenvolvidas do país, permanecendo menos tempo no emprego e tendendo a se sujeitar com mais intensidade a vínculos empregatícios instáveis e precários.

Nos anos de 1987 e 1998, a análise comparativa teve sua base de dados restrita à região metropolitana de São Paulo. Paixão (2003, 124127) percebeu que houve uma deterioração do mercado de trabalho para brancos e negros. Segundo o autor, a base de dados estudada permitiu in- 


\section{hevista pll paעtg}

\} DESUMANIZAÇÃO DA POPULAÇÃO NEGRA - ALMEIRA, M. S. \}

ferir que a perda da qualidade do mercado de trabalho incidiu de modo mais forte sobre os afrodescendentes. Isso pode ser comprovado da seguinte forma:

Entre os negros, as formas de ocupação pioraram proporcionalmente mais do que para os brancos. Entre os afrodescendentes, aumentaram as modalidades de empregos autônomos, informais e serviços domésticos;

Entre os negros, fundamentalmente entre as mulheres trabalhadoras com mais de 24 anos, o desemprego cresceu com uma intensidade maior do que entre brancos. Desta forma, ampliou-se o abismo na remuneração entre brancos e negros na região metropolitana de São Paulo (PAIXÃO, 2003, p. 132).

Cabe ressaltar, ainda, que, reconhecendo o limite da análise desses indicadores, podemos dizer que a desigualdade sociorracial é de ordem política. Ou seja, a escolha de modelos econômicos não é neutra e, de acordo com a sua teleologia, ela incluirá ou não os grupos raciais, garantirá ou não, democraticamente, direitos sociais. Se hoje, no Brasil, a sociedade civil luta pela real democracia racial, através do protagonismo dos movimentos negros, a materialização desse princípio será, de fato, na inclusão real dos segmentos negros no acesso aos bens e serviços, sobretudo à riqueza produzida.

Ao longo da história republicana, os sucessivos modelos de desenvolvimento sugeridos pelos governos não conseguiram contemplar os negros nem reduzir as disparidades sociorraciais. Sobre isso, diz Paixão (2003, p. 133):

é absolutamente razoável imaginarmos que, dentro de um contexto de franco desenvolvimento da economia de meado do século XX, e dada as barreiras à integração social dos afro-descendentes, os abismos das condições sociais de brancos e negros tenham se ampliado neste período. Ou seja, o modelo paternalista de relações raciais e as estratégias pessoais de ascensão social individual nã̃o permitiram que o processo de mobilidade social positiva dos afro-descendentes se desse de forma massiva, ou que as desigualdades raciais se reduzissem. Nesse sentido, também o modelo econômico baseado na presença do Estado na economia também não serviu para a redução das disparidades sociais no Brasil. Assim se relacionarmos a este cenário com as conclusões a que chegamos quando estudamos os anos neoliberais, verificamos que os afro-descendentes potencialmente se veem na triste situação de que, quando a economia cresce, eles ganham menos, quando a economia se retrai, eles perdem mais.

\section{Analfabetismo}

Os estudos dos indicadores revelaram um quadro desanimador em relação à condição de vida da população negra, em particular das mu- 


\section{AeVistg all paUtg}

\} DESUMANIZAÇÃO DA POPULAÇÃO NEGRA - ALMEIRA, M. S. \}

Iheres negras. Tomemos como referência o Índice de Desenvolvimento Humano (IDH). Esse índice é calculado pela Organização das Nações Unidas (ONU) para investigar a qualidade de vida nos países, em escala global, com base na distribuição de renda, educação e condições de saúde. Segundo esse estudo, em 2007 o Brasil estava em 70ํ lugar no ranking mundial, sendo considerado um país de desenvolvimento humano elevado. No entanto, quando os dados são observados segundo a raça/cor, a realidade muda radicalmente. Assim, ao relacionar o IDH do Brasil com o quesito raça/cor dos brasileiros, constata-se que a qualidade de vida da população negra é pior que a da população branca (PAIXÃO, 2003).

A importante pesquisa realizada por Paixão (apud SANTOS, 2009, p. 19, sobre as taxas de analfabetismo com base nos dados do Censo Demográfico de 2000, revela que:

Entre a população brasileira maior de 15 anos havia 15,3 milhões de analfabetos e 32,8 de analfabetos funcionais (pessoas com menos de quatro anos de estudos). [...] Dos 15,3 milhões de analfabetos brasileiros, 9,7 milhões eram negros. Entre os 32,7 milhões de analfabetos funcionais, os negros totalizavam 18,8 milhões de pessoas. Assim, segundo os indicadores do Censo Demográfico de 2000, a taxa de analfabetismo dos negros maiores de 15 anos, em todo Brasil, era de $18,7 \%$, e a taxa de analfabetismo funcional da população negra maior de 15 anos era de 36,1\%. Estes percentuais eram substancialmente maiores do que o verificado entre a população branca, cujos percentuais de analfabetismo e de analfabetismo funcional eram de, respectivamente, $8,3 \%$ e $20,8 \%$. Ou seja, em relação ao indicador de analfabetismo funcional, a taxa verificada entre os negros era $73 \%$ maior do que a observada entre os brancos; no caso da taxa de analfabetismo, este valor relativo, era $125 \%$ maior.

\section{Saúde}

O Sistema Único de Saúde (SUS) foi consagrado na Constituição de 1988 como um dos pilares da Seguridade Social, com o objetivo de garantir o acesso universal e gratuito de todos os cidadãos brasileiros, independente de sexo, raça, cor etc. Segundo pesquisa realizada pelo Ipea (RETRATO, 2011) com a participação da ONU Mulheres, da Secretaria de Políticas para as Mulheres (SPM) e da Secretaria de Políticas de Promoção da Igualdade Racial (Unifem/SPM/SEPPIR), o SUS foi responsável por $63,5 \%$ dos atendimentos e 69,3\% das internações ocorridas no país. Quando a análise é realizada desagregando os dados por raça/cor, percebe-se uma diferença significativa entre a população branca e negra: para os brancos, $54 \%$ dos atendimentos e $59 \%$ das internações foram cobertos pelo SUS; para os negros, as proporções foram de $76 \%$ e $81,3 \%$, respectivamente. Este resultado indica o quanto a população negra depende do SUS. 


\section{hevista pll paעtg}

\} DESUMANIZAÇÃO DA POPULAÇÃO NEGRA - ALMEIRA, M. S. \}

No entanto, apesar da importância da atuação do SUS na saúde de nossa população, um estudo inédito realizado por pesquisadores do Ipea (MARINHO; CARDOSO; ALMEIDA 2011, p. 26-38) - dados fornecidos pela Associação Brasileira de Transplantes de Órgãos (ABTO) - sobre os efeitos das desigualdades sociais brasileiras, no período de 1995 a 2004, indicam que, nas cirurgias de transplantes de órgãos como coração, fígado, rim, pâncreas e pulmão, a maioria dos transplantados são homens da cor branca. De acordo com esse estudo, a cada quatro receptores de coração, três são homens; $56 \%$ dos transplantados têm a cor da pele branca. No transplante de fígado, $63 \%$ dos receptores são homens e $37 \%$ mulheres. A cada dez transplantes de fígado, oito são para pessoas brancas.

Segundo a análise do Ipea, do estudo acima citado (MARINHO; CARDOSO; ALMEIDA, 2011, p. 30- 36), homens e mulheres são igualmente atendidos nos transplantes de pâncreas, mas 93\% dos atendidos são brancos. A maioria absoluta de receptores de pulmão também são homens $(65 \%)$ e pessoas brancas $(77 \%)$. O mesmo fenômeno ocorre com o transplante de rim: $61 \%$ dos receptores são homens; $69 \%$ das pessoas atendidas têm pele clara.

'O sistema é desigual na ponta cirurgia de alta complexidade porque é desigual na entrada', assinala o economista, ao dizer que quando o SUS tem excelência no atendimento o acesso não é para todos: ' $N$ a hora que funciona, quem se apropria são as pessoas mais bem posicionadas socialmente'. (MARINHO, 2011, s.p.).

Isto posto, fica claro que as desigualdades sociais e as clivagens de raça e gênero afetam a população negra em seu conjunto, no que tange ao acesso aos transplantes de órgãos.

\section{Homicídio}

Mais uma expressão da violência racial no Brasil diz respeito ao número exorbitante de mortes decorrente de homicídio, afetando drasticamente o jovem negro e, consequentemente, a constituição da família negra. Os índices de homicídio, apresentados no Mapa da Violência de 2011, da população total por raça/cor, expressam diferenças regionais alarmantes (WAISELFISZ, 2011).

Para o ano de 2005, o índice nacional era de 67, 1. Ou seja, o estudo indica que, nesse ano, morreram proporcionalmente $67,1 \%$ mais negros do que brancos. Verifica-se que as taxas de homicídio de brancos caíram de 20, 6 para 15, 9 a cada 100 mil. Houve uma queda de 22, 7\% entre 2002 e 2008. Já na população negra, as taxas passaram de 30, 0, em 2002, para 33, 6 homicídios a cada 100 mil negros em 2008, o que representa um aumento de 12, 1\% (WAISELFISZ, 2011). 


\section{ReVistg all paUtg}

\} DESUMANIZAÇÃO DA POPULAÇÃO NEGRA - ALMEIRA, M. S. \}

Em 2002, o índice nacional de vitimização negra foi de 45, 6. Isto é, nesse ano, morreram proporcionalmente 45, 6\% mais negros do que brancos. Apenas três anos mais tarde, em 2005, esse índice pulou para 80,7 , (morreram proporcionalmente $67,1 \%$ mais negros que brancos). Já em 2008, um novo patamar: morreram proporcionalmente $111,2 \%$ mais negros que brancos, ou seja, mais do que o dobro! (WAISELFISZ, 2011, p. 57).

O Mapa da Violência de 2013, relativo ao tema Homicídios e Juventude no Brasil, apresenta, entre as conclusões, um quadro desolador acerca da ação genocida permanente perpetrada contra a juventude negra. Segundo os estudos existentes, coincide a afirmação de que a vitimização homicida no país é fundamentalmente masculina (WAISELFISZ, 2013, p. 73), dado apontado pelo autor no relatório de 2011. (WAISELFISZ, 2011, p. 64).

O Sistema de Informações de Mortalidade do Ministério da Saúde inicia a divulgação de seus dados em 1979, mas somente em 1996 começa a oferecer informações acerca do quesito raça/cor com um grau elevado de notificação. O relatório informa que, até 2002, a cobertura desses dados foi deficitária, motivo pelo qual se julgou procedente começar a analisar essas informações a partir de 2002, quando a cobertura alcançou um patamar considerado razoável: acima de $90 \%$ dos registros de homicídio com identificação da raça/cor da vítima. (WAISELFISZ, 2013, p. 83).

O relatório aponta uma acentuada tendência de queda no número absoluto de homicídios entre a população branca, e de aumento nos números de vítimas entre a população negra. Essa tendência pode ser observada no conjunto da população, e de forma bem mais pronunciada na população jovem.

Podemos verificar que, no conjunto da população (WAISELFISZ, 2013, p. 87-88):

O número de vítimas brancas caiu de 18.867, em 2002, para 13.895 em 2011, o que representou um significativo decréscimo: 26, 4\%;

As vítimas negras cresceram de 26.952 para 35.297, no mesmo período; isto é, houve um aumento de 30, 6\%;

Assim, a participação branca no total de homicídios do país caiu de $41 \%$, em 2002, para 28, 2\% em 2011. A participação negra, já elevada em 2002, com 58, 6\%, cresce mais ainda: vai para $71.4 \%$;

Com esse diferencial, a vitimização negra passa de 42, 9\%, em 2002 - nesse ano, morreram proporcionalmente 42, 9\% mais vítimas negras do que brancas - para 153, 4\% em 2011, num crescimento contínuo anual dessa vitimização.

Em relação à população jovem, entre 15 e 24 anos de idade, a evolução é semelhante, mas acontece de forma bem mais intensa (WAISELFISZ, 2013, p.88):

O número de homicídios de jovens brancos cai de 6.596, em 2002, para 3.973 em 2011: queda de $39,8 \%$, bem maior que a do conjunto da população, de $26,4 \%$; 
Já as vítimas negras, entre os jovens, cresceram de 11.321 para 13.405, ou seja, um aumento de 24, 1\%;

Assim, a participação dos jovens brancos no total de homicídios juvenis do país caiu de 36,7\%, em 2002, para 22,8\% em 2011. Por sua vez, a participação dos jovens negros, que era de $63 \%$, uma porcentagem muito elevada já em 2002, cresceu ainda mais, indo para $76,9 \%$;

Com esse diferencial de ritmos, a vitimização de jovens negros passou de 71, 6\% em 2002 - nesse ano morreram proporcionalmente 71, $6 \%$ mais jovens negros que brancos - para 237, 4\% em 2011, porcentagem maior ainda que a pesada vitimização da população total que, nesse ano, foi de $153,4 \%$.

Para finalizar, apresento uma breve análise de Alves (2006, p. 2) sobre o projeto de segurança pública. Expressando a forma como o Estado e seus agentes, que operam cotidianamente, têm sido objeto de críticas da sociedade civil e das organizações do Movimento Negro. Alia-se a isto o movimento de mulheres negras que perderam seus filhos, seja pela ação do tráfico ou de seus agentes, e sua dor pouco ou nada visível na sociedade brasileira, apesar das denúncias.

Alves (2006, p. 2) afirma que a crise do sistema de segurança pública no Brasil e a crise de legitimidade da ação policial expõem:

as fraturas de uma sociedade marcadamente desigual no acesso de brancos e negros à justiça e aos bens sociais. Aqui a segurança pública sempre foi vista sob a rubrica da militarização, da brutalidade contra os negros e do combate aos inimigos internos sob o eco da ordem. As prisões são concebidas como depósito de seres humanos inviáveis. Os maus-tratos e a tortura foram institucionalizados no imaginário autoritário da polícia [...]. Assim se arranca de jovens negros confissão de crimes, se forja flagrantes baseados na cor da pele, se criminaliza os pobres.

\section{Diáspora e genocídio: uma primeira aproximação}

Sobre o projeto de colonialidade, breves considerações.

Para Clovis Moura (1994, p. 125), a aventura colonial dos europeus no século XV não foi exclusivamente um "ato de expansionismo geográfico, com o objetivo de conseguir novas áreas de dominação e rotas comerciais marítimas". Estes foram os objetivos visíveis desse processo violento. Foi um processo vertical, tratado pelo autor como complicador étnico, mutilador e estrangulador cultural. Para ele,

complicador étnico porque introduziu compulsoriamente nas áreas colonizadas - América do Norte, Caribe e América do Sul - o componente africano que veio não apenas dinamizar demograficamente essas áreas, mas, também, involuntariamente consolidar, com seu 
trabalho o escravismo nessas colônias. Mutilador e estrangulador cultural Poe que impôs pela violência, direta dou indireta, os seus padrões culturais e valores sociais usando para isso desde a morte e a tortura até a catequese refinada chamada de evangelização para dominar os povos escravizados

Se, no plano cultural, processos assimiladores foram engendrados para "encobrir o outro", nos termos de Dussel (1993, p.8), no plano social os povos autóctones e negros africanos escravizados eram alocados nos extratos inferiorizados de trabalho. A divisão racial do trabalho, segundo Moura (1994, p. 125), irá expressar

uma divisão do trabalho rigidamente hierarquizada [e] colocava as populações autóctones ou africanas importadas nos últimos patamares da escala social, impondo como critério extremo de controle o estabelecimento da escravidão e da servidão.

Contudo, mesmo em uma realidade adversa, os negros africanos e seus descendentes não tiveram outra opção senão lutar para sobreviver aos abusos a que foram submetidos. Na dinâmica colonial, a imposição dos padrões civilizatórios eurocêntricos pelos grupos dominantes não foi impingida sem que houvesse resistência dos grupos dominados. Muito pelo contrário, a memória da Diáspora Negra não só traz a marca da escravidão, como também das lutas de negação desse padrão de sociabilidade. A escravidão negra não pode ser esquecida porque, contra ela, houve muitas resistências: no Brasil. Isto se deu através de fugas, assassinatos, levantes e construção de quilombos, sendo o mais conhecido o Quilombo de Palmares.

Konrad (2007, p. 116) afirma que uma das poucas referências sobre a República de Palmares chegou até nós através do estudo intitulado Relação das guerras feitas aos Palmares de Pernambuco no tempo do governador D. Pedro de Almeida, de 1675-1678. Diz o autor que a denominação República de Palmares refere-se à reunião de vários quilombos, durando aproximadamente um século (1597-1697) na Serra da Barriga, em Alagoas. Outra experiência importante foi o levante dos negros escravizados no Haiti, iniciado em 1791 sob a condução de Toussaint L'Ouverture.

Ressalta-se que o tráfico transatlântico, que perdurou por mais de trezentos anos no Brasil (o último país a abolir a escravidão no Planeta), só foi considerado crime contra a humanidade em 2001, na Conferência de Durban (África do Sul). Embora o regime escravo tenha findado formalmente em 1888, o Estado brasileiro não apresentou nenhuma política reparatória para a população negra e sequer garantiu direitos de cidadania no regime republicano vindouro.

De maneira límpida, a memória da escravidão está viva nas mazelas experimentadas pela população negra até os dias de hoje. As refrações 


\section{hevista pll paעtg}

\} DESUMANIZAÇÃO DA POPULAÇÃO NEGRA - ALMEIRA, M. S. \}

da questão social que incidem sobre esta população têm suas raízes na escravidão e foram reconfiguradas no trabalho livre. Assim, o tráfico de africanos, no século XV, é concebido, neste trabalho, como um rentável investimento comercial que envolveu elites lusitanas, africanas e brasileiras. Essa economia garantiu o enriquecimento de uma aristocracia que acumulou grandes fortunas, alicerçada em terras e escravos, retirando benefícios do trabalho escravizado.

O tráfico de negros africanos era um investimento tão lucrativo que, mesmo na clandestinidade, após a sua proibição oficial em setembro de 1850 (a primeira tentativa de proibição do tráfico se deu em 7 de novembro de 1831), perdurou auferindo lucro e prestígio social.

Estudos demonstram que, após a repressão inglesa, a dinâmica do tráfico mudou nas duas margens do Atlântico: na África, houve um deslocamento do embarque de africanos de Luanda para o norte de Angola ou para a Costa Oriental, sobretudo após a proibição do tráfico nas colônias portuguesas, em 1836. No Brasil, os desembarques também foram reordenados para fugir à repressão. As praias litorâneas mais afastadas do controle do Estado passaram a acomodar os novos fluxos de africanos escravizados, e novas edificações foram construídas para receber esse contingente, após a quarta década dos anos de 1800. Essa reordenação da economia ilegal traria novas implicações econômicas, políticas e culturais - Pessoa (2013, p.46) chama a atenção para outras formas de deslocamento do tráfico de negros africanos, demandadas pela proibição. Segundo o autor, outro deslocamento demográfico de escravos é observado para áreas economicamente mais desenvolvidas, situadas na Região Sudeste, sugerindo o tráfico interprovincial para atender ao novo ciclo econômico em evidência: o ciclo do café.

O tráfico negreiro, portanto, consistiu no sequestro forçado de milhões de vidas, e foi, indubitavelmente, a maior extradição não consentida de um incomensurável contingente de pessoas na história da humanidade, inaugurando o pioneirismo lusitano nesse tipo de comércio. Estudos sobre a escravidão afirmam que o Brasil recebeu em torno de cinco milhões de africanos, tornando-se o maior país com população negra fora do continente africano (PRANDI, 2000, p. 52).

Onde quer que a escravidão tenha sido uma realidade, lançou mão de métodos violentos, torturantes, agindo contra a integridade física e psicológica dos grupos escravizados. O racismo contemporâneo guarda em sua memória marcas desse passado. Portanto, não existiu escravidão mais ou menos agressiva.

Florentino (2007) destaca uma passagem do livro Portugal e a escravatura, de autoria de João Pedro Marques, no qual este autor nos apresenta uma observação do historiador norte-americano Joseph Miller:

a cada 100 escravos apanhados em Angola, 36 morriam entre a captura e o transporte até a costa, 7 à espera de embarque nos negreiros, 
6 pereciam durante a travessia oceânica e 23 feneciam nos primeiros anos de Brasil, ou seja, em 4 anos, $72 \%$ de mortalidade acumulada. (FLORENTINO, 2007, p. 1141).

Do mesmo modo, Jacob Gorender situa a forma cruel de gestão da força de trabalho negra escravizada nos anos de 1800, na ilha de São Domingos, atual Haiti, apresentada no livro Jacobinos negros, do marxista C.L. R. James. Este autor assevera que

O tratamento dado pelos escravistas aos seus servidores era terrivelmente cruel. A par do trabalho, que esgotava rapidamente as energias, pesavam sobre os escravos a alimentação escassa, a moradia sórdida e a inexistência de assistência médica. A labuta diária se processava durante longas jornadas, sob acionamento freqüente do açoite dos feitores. Qualquer expressão recalcitrante era logo duramente castigada. Os mais indisciplinados sofriam o castigo de serem enterrados de pé, apenas com a cabeça de fora. Assim imobilizados, acabavam mortos depois de sofrer a horrível tortura de ter o rosto lentamente devorados pelos insetos e abutres. (GORENDER, 2004, p. 297).

A República de modo algum trouxe melhoria para a população negra. O modus operandi, através do qual o Estado autuou e atua no atendimento às necessidades dos negros e negras, tem demonstrado que seus problemas na Diáspora Negra, na grande maioria, estão sem respostas concretas às principais necessidades. O Estado tem entregado os negros à sua própria sorte.

Somente após anos de denúncia do racismo e de suas mazelas é que o movimento negro tem feito algumas alianças com outros setores progressistas no Brasil, na luta pelo combate ao racismo. No entanto, as ações construídas ainda não são suficientes para mobilizar outros segmentos sociais ou mesmo a própria população negra. A consciência do processo de sujeição e exploração não tem sido suficientemente criticada para derrubar o projeto hegemônico em curso.

Hoje, na prática, o Estado neoliberal, sobretudo na Era Lula e no governo da Presidenta Dilma Rousseff, tem apoiado as políticas afirmativas para a população negra. Outro fato importante foi a aprovação das ações afirmativas para o ensino superior pelo Supremo Tribunal Federal.

Todos esses ganhos, sem dúvida, foram conquistas dos movimentos negros que, mediante várias estratégias de pressão, apostaram na manutenção das políticas compensatórias para a população negra, como alternativa possível para sua inserção em sistemas de proteção social, garantindo o acesso aos bens e serviços em atenção a suas necessidades.

Concordo plenamente com as medidas de reparação histórica, mas essas políticas não têm sido suficientes para impedir o quadro da violência sobre a população negra. Este quadro está se materializa no desem- 


\section{hevista pll paעtg}

\} DESUMANIZAÇÃO DA POPULAÇÃO NEGRA - ALMEIRA, M. S. \}

prego estrutural, no subemprego, no analfabetismo, na mortalidade materna da mulher negra, na ausência de uma política de redução de danos para os usuários de álcool e outras drogas, que sejam condizentes com o atendimento à saúde de qualidade e no acesso à justiça. É expressão dessa violência, também, o genocídio da juventude negra, no qual expressiva massa de jovens negros é abatida pelo tráfico ou pela ação truculenta da polícia e dos demais agentes da "segurança pública".

Vargas (2010) considera importante que a análise acadêmica dos problemas da Diáspora Negra seja acompanhada de sua dimensão política. Não há análise neutra nem política de Estado que não opte por um projeto de sociedade.

A ascensão de Barack Obama à presidência da república traz questões importantes acerca do destino da população negra norte-americana, sobretudo no que diz respeito ao investimento (ou não) em políticas sociais que atendam os negros nos Estados Unidos da América (EUA).

Os EUA têm um grande contingente de negros em situação de privação de liberdade, variando em torno de um milhão de pessoas. Segundo Angela Davis (2014), nos EUA existem mais homens negros em prisões do que em universidades. Para ela, o racismo de hoje é mais perigoso. "Pessoas que estão encarceradas dizem que um homem negro na Casa Branca não é suficiente para anular um milhão de homens negros na casa-grande, ou seja, no sistema carcerário." (DAVIS, 2013). Sem políticas sociais, o cárcere se torna a alternativa possível para o homem negro norte-americano, diz a autora.

A contribuição de Almeida (2011, p. 87) no emprego do conceito de diáspora, nos estudos sobre políticas de ação afirmativa no Brasil, devese à possibilidade de o termo iluminar a experiência negra da dispersão forçada dos africanos pelo tráfico, como mencionado anteriormente. Segundo a autora, essa concepção foi empregada inicialmente para explicar a experiência do povo judeu, "evocando o seu traumático exílio de uma prática histórica e sua dispersão por vários países." (CASHIMORE apud ALMEIDA, 2011, p. 87).

Segundo essa perspectiva, o conceito de diáspora tem uma conotação negativa ligada à dispersão forçada, à vitimização, à alienação etc. Todavia, estudos contemporâneos politizam a categoria de diáspora como um termo utilizado para descrever comunidades transnacionais, cujas redes sociais, econômicas e políticas atravessam fronteiras das Nações-Estados. Processos mundiais no plano étnico-racial (migrações, refugiados de guerra, xenofobia, racismo, resistências etc.) trazem à cena pública novas questões, desenhando as novas faces da questão social e suas refrações na experiência de vida da população negra.

Baseada em Vargas (2010), proponho uma nova concepção de diáspora que amplie as possibilidades de libertação do povo negro dos processos antinegros que incidem sobre ele. 


\section{ReVistg all paUtg}

\} DESUMANIZAÇÃO DA POPULAÇÃO NEGRA - ALMEIRA, M. S. \}

A Diáspora Negra, assim concebida, é marcada por vários processos genocidas antinegros, não apenas predominantes, mas fundantes do Estado-Nação. Talvez uma concepção alargada de Diáspora Negra, que relativize as particularidades de cada realidade social (e suas nacionalidades), permita identificar os processos de genocídio vividos pela população negra, bem como as alternativas políticas que se abrem no confronto e na luta por direitos com vistas à libertação dessa população.

Vargas (2010, p. 34) adota o conceito complementar de diáspora que, mesmo reconhecendo suas múltiplas expressões performáticas e políticas inerentes, foca as análises no terror racial e no genocídio antinegro como característica fundante. Diz o autor que

Nega-se aos membros das comunidades negras na diáspora o direito de sobreviver plenamente como cidadãos ou seres humanos- o genocídio como um fato constitui o sustentáculo a base de onde as várias manifestações da negritude que definem a diáspora são construídas.

deve

Vargas (2010, p. 34) ainda nos informa que o conceito de diáspora

localizar as experiências comuns de estado onde há subjugação racial (obviamente não estrita a hostilidade policial), desemprego desproporcional e encarceramento em massa, morte prematura e doenças preveníveis entre outros fatos bastante compartilhados entre negros com a base de onde a diáspora existe luta e perece. Como um processo e uma condição [...], a diáspora negra necessariamente se apoia, desafia e sobrevive a tais fenômenos transnacionais.

Essa abordagem traz como imperativo o engajamento na luta política, na materialização da práxis negra como condição de sobrevivência e como devir do processo libertário imanente da Diáspora Negra. Este deve ser pensado pelos negros e negras e, a meu ver, dialogado com os aliados políticos igualmente subjugados e explorados na sociedade burguesa, para superação da ordem capitalista, cujo horizonte é a emancipação humana.

Nestes termos, Vargas (2010, p. 34) questiona os limites que o Estado-Nação impõe à condição negra. Ou seja, "a impossibilidade de cidadania plena, a possibilidade de uma humanidade integralmente reconhecida e vivida, a impossibilidade de não 'magnetizar' balas."

Assim, quais as possibilidades políticas reais para os membros da Diáspora Negra? Quais as alternativas teórico-práticas, culturais e sociais dos membros da Diáspora Negra, elaboradas permanentemente contra as violências do Estado, contra o racismo institucional e a sociedade que não está em seu favor? Decerto, se tomamos teoricamente a Diáspora Negra como genocídio, imputamos seu estado permanente de resistência e rebelião. 


\section{hevista pll paעtg}

\} DESUMANIZAÇÃO DA POPULAÇÃO NEGRA - ALMEIRA, M. S. \}

Evidentemente, para o autor, o foco e o horizonte de conhecimento são as práticas e estratégias de luta dos grupos de resistência que se desenvolvem de forma coletiva, com base em esforços transnacionais. Para esta concepção, a Diáspora Negra não é apenas uma geografia da morte (VARGAS, 2010), mas um conjunto de conhecimentos políticos, ontológicos, imanentes e insurgentes.

Neste sentido, as alternativas emancipatórias são possíveis na história, uma vez que a condição de genocídio é um princípio tácito do capitalismo, dada a impossibilidade de a condição negra ser plenamente experimentada pela comunidade. Por esse motivo, adensa contraditoriamente essa força motora transformadora, possível de ser potencializada pela luta política organizada pela comunidade negra na Diáspora Negra.

O autor apresenta uma nova abordagem que implica em uma práxis negra. Opta por utilizar a categoria negro e não africano. Compreende a importância horizontal e constitutiva do papel do continente nas atuais "experiências multidimensionais de processos relacionados à diáspora" (VARGAS, 2010, p. 35), mas chama atenção para processos e fatos articulados que produzem o genocídio fora do continente.

Para Vargas (2010, p. 35), a luta da comunidade negra, como estratégia de sobrevivência, relaciona-se mais com a experiência concreta dessas populações contra o genocídio em suas nações, base sobre a qual as identidades e políticas negras são experimentadas na diáspora. Portanto,

a Diáspora Negra nas Américas, incluindo os Estados Unidos, embora às vezes reconhecida por engendrar vários desafios para seus membros, é muito raramente criticada por constitutivamente criar e manter condições sob as quais a sobrevivência da comunidade é constantemente desafiada. A ênfase sobre a diáspora visa colocar os processos e condições genocidas no centro e à frente do que constitui as bases sobre as quais as identidades e políticas negras são experimentadas através da diáspora, especialmente nas Américas. Nações africanas e americana tem em comum os desafios de sobrevivência de suas comunidades negras como constitutiva de suas experiências. Assim sendo, sua ligação À diáspora tem menos relação com a localização geográfico-nacional ou com questões de origem do que com a experiência transnacional dividida na luta contra o genocídio.

A novidade dessa abordagem é que ela desloca a análise para as circunstâncias políticas e econômicas de base. Nestes termos, circunstâncias aparentemente distintas tornam-se significativas se articuladas buscando unidade supranacional e social, que atinge desproporcionalmente as comunidades negras na Diáspora.

Em outras palavras, precisamos nos aproximar daquilo que foi considerado descontínuo, dado como separado, desestabilizado. 
Desestabilizamos o que a hegemonia deu como coerente ou fixo; tornar semelhante o que parece distinto, difuso ou idiossincrático; trazer ao primeiro plano o que é latente e, portanto, poderoso em sua aparente ausência; e analisar o que é aparentemente autoevidente, o que a hegemonia dá como senso comum e natural, mas que devemos ler como gestos do poder que empregam a violência para normatizar e disciplinar. (ALEXANDER apud VARGAS, 2010, p. 36).

Se precisamos identificar as refrações da questão social, devemos cotejar suas dimensões ocultadas ou invisibilizadas pela lente do imperialismo e do colonialismo, nas quais são privilegiadas as relações sociais hierárquicas estruturadas pelo racismo patriarcal e pela dominação de classe. Segundo Vargas (2010), a dimensão oculta e desprivilegiada se articulada com outros fatos aparentemente irrelevantes, tornando-se significativos como uma constelação supranacional que atinge de forma desigual e desproporcional as populações negras na diáspora.

Contudo, faz-se mister a compreensão e documentação das experiências da população negra na diáspora e como ela lida com a violação de suas necessidades humanas. Requer uma práxis comprometida com as experiências da população negra. Ou seja, um engajamento como estratégias e teorias políticas que permitam desvelar os processos ocultos de invisibilização, através dos quais pode-se desafiar a experiência de genocídio na Diáspora Negra.

No que se refere à noção de genocídio, a concepção moderna do termo é atribuída ao jurista polonês Raphael Lemkin, que migrou da colônia para os Estados Unidos em 1939, em decorrência do holocausto judeu. Sua contribuição apareceu em 1944 no Axis rule in occupied Europe, compreendendo uma perspectiva multifacetada. Não se restringia às ações de assassinatos simplesmente, mas às ações que infringiam a liberdade, a dignidade e a segurança de um grupo.

Vargas (2010) adota a definição de genocídio pautada e aprovada na Convenção sobre a Prevenção e a Repressão do Crime de Genocídio, aprovada pela Resolução 260 A (III) do Conselho Geral das Nações Unidas de 9 de dezembro de 1848, efetivada em 1951.

De acordo com o artigo II da Convenção (VARGAS, 2010, p. 38), genocídio é entendido como:

Os atos abaixo indicados, cometidos com intenção de destruir, no todo ou em parte, um grupo nacional, racial ou religioso, tais como:

a) Assassinato de membros do grupo;

b) Atentado grave à integridade física e mental de membros do grupo;

c) Submissão deliberada do grupo a condições de existência que acarretarão a sua destruição física, total ou parcial;

d) Medidas destinadas a impedir os nascimentos no seio do grupo;

e) Transferência forçada de crianças de um grupo para outro grupo. 


\section{hevista pll paעtg}

\} DESUMANIZAÇÃO DA POPULAÇÃO NEGRA - ALMEIRA, M. S. \}

O racismo, o preconceito e a discriminação racial são relações sociais antagônicas à ontologia do ser social, fundante da teoria social crítica. Nesse sentido, a totalidade social da situação de discriminação racial e a violência contra a população da Diáspora Negra, com seus sujeitos concretos (crianças negras, mulheres negras, homens negros, jovens negros/as, idosos/ as negros/as), deve ser compreendida a partir da contribuição teórico-crítica. $\mathrm{O}$ foco é dado nos processos de genocídio intrínsecos às relações sociais capitalistas nas dimensões econômicas, mas não desprivilegiando a luta de classe.

Nesse terreno contraditório, torna-se fundamental a compreensão dos elementos ideológicos, como o racismo e o sexismo, que incidem nas relações sociais, engendrando políticas de branquidade que não atendem às necessidades humanas da população negra. Essas políticas alimentam as desvantagens da população negra porque não vislumbram as experiências dela na Diáspora Negra como sendo genocídio. São vislumbradas, porém, como respostas suficientes ao enquadramento, disciplinamento do grupo populacional dominado/oprimido ao projeto de sociabilidade burguesa sob a égide do capital.

Cabe destacar três pontos que considero importantes nessa reflexão, mas que, dados os limites deste estudo, serão aprofundados em futuras investigações.

O primeiro diz respeito às conquistas no plano político e social, alçadas pelo Movimento Negro Brasileiro nos últimos vinte anos. São as experiências da comunidade negra, registradas nos limites "permitidos" da experiência diaspórica, em 1990 - restrita à experiência isolada de alguns ativistas negros/as ou de instituições dos movimentos negros.

Na época, a presença de negros e negras na universidade brasileira era inferior a $2 \%$ da população negra do país. O Censo de 2000 já apontava a porcentagem de $47 \%$ da população autodeclarando-se preta e parda. A produção e circulação de textos e pesquisas são ampliadas a partir de 1996, num incremento vertiginoso. Isso deve-se ao fato de o período apresentar as condições objetivas de grande vitalidade das lutas do Movimento Negro (ALMEIDA, 2011).

Nessa conjuntura, marcada pelas mobilizações antirracistas decorrentes da Marcha Zumbi dos Palmares - Contra o Racismo, pela Cidadania pela vida, em 1995, em Brasília (DF), os rumos da luta antirracista no Brasil apontaram para a defesa das políticas de ações afirmativas, uma vez que foi constatada a ineficácia das políticas universais na educação implementadas na ditadura. Elas não atendiam, de fato, à grande massa da população negra, além de não se comprometerem com as propostas de combate ao racismo formuladas pelos movimentos negros. (ALMEIDA, 2011, p. 126).

Todavia, o cenário expressa profundas contradições materializadas na violência policial militarizada, na segregação espacial, no desemprego, na morte prematura de mulheres e adolescentes negras, no exter- 


\section{ReVistg all paUtg}

\} DESUMANIZAÇÃO DA POPULAÇÃO NEGRA - ALMEIRA, M. S. \}

mínio da juventude negra, na defesa emocionada dos setores reacionários em defesa da redução da maioridade penal, no encarceramento maciço no sistema prisional e no acesso desigual à justiça. Isto pouco tem ajudado os movimentos contra o genocídio da população negra, ao terem seus direitos humanos preservados quando assumem uma atitude de denúncia ao racismo institucional perpetrado pelos agentes policiais ou militares.

O segundo ponto é a defesa da categoria de raça como sociológica de análise, ou seja, a raça como construção social. A experiência brasileira mostrou que uma das estratégias para desmontar o conceito racista de democracia racial foi a afirmação da identidade social negra como contraponto legítimo forjado pelos movimentos negros, em resposta ao projeto de branqueamento. Por outro lado, longe de afastar qualquer tentativa de hierarquização entre os grupos raciais e as desvantagens da população negra no acesso às políticas sociais e econômicas do país, o conceito de miscigenação irá difundir, ideologicamente, as concepções positivas do branqueamento e trará valores negativos aos atributos da raça negra.

Portanto, raça, como é concebida hoje, nada tem de biológico. É um conceito político que expressa relações de poder e dominação. É uma categoria de hierarquização social e opera na produção de desigualdades sociais. A utilização do conceito de raça abriga um histórico de dominação dos homens brancos ocidentais sobre o resto do mundo. Classe e patriarcado são atributos da sociedade patriarcal, e estão na origem da supremacia branca. Assim, o conceito de raça implica igualmente no conceito de racismo com os processos de interiorização resultantes.

A sociedade brasileira, desde o início do século XXI, tem assistido a uma disputa severa entre aqueles que defendem o critério étnico-racial como marcador de acesso a direitos historicamente negados à população negra, e aqueles que admitem que a questão é meramente de classe. Movimentos em defesa ou contrários às cotas para a população negra nas universidades, e até mesmo a judicialização do tema no Supremo Tribunal Federal, demonstram a arena de luta no campo dos direitos. Há, portanto, dificuldade em trabalhar com argumentos que situam negros e negras como sujeitos de direitos.

O que está em jogo é a dificuldade da supremacia branca e de seus agentes de aceitarem a humanidade negra e sua capacidade de disputa (o que não é esperado nem desejado em sociedades hierarquizadas a partir do critério racial). A supremacia branca e o terror racial impingem processos de sujeição/exploração contínuos, sem tréguas para os grupos dominados contrários à sujeição supostamente intocável das populações negras.

Estes fatos sinalizam o quanto está em disputa a garantia das ações afirmativas, cujo direito pode ser extinto se a sua manutenção contrariar os interesses econômicos e políticos da classe dominante.

Observou-se, por exemplo, no ingresso nas universidades públicas, processos fraudulentos de alunos brancos na reserva de vagas para negros, conforme foram noticiados pela mídia televisiva e escrita. 


\section{hevista pll paעtg}

\} DESUMANIZAÇÃO DA POPULAÇÃO NEGRA - ALMEIRA, M. S. \}

O terceiro ponto diz respeito à necessidade de aprofundamento dos estudos e pesquisas sobre o alcance das políticas econômicas do Governo Lula, continuadas nos governos Dilma Rousseff, no que diz respeito ao combate a processos de genocídio, tal como entendido neste trabalho.

Concluo que, mais uma vez, o Governo Dilma caminha para não tocar nas questões centrais concernentes ao enfrentamento das desigualdades sociorraciais. Em tempos neoliberais, parece-me que as saídas da crise encontram-se envoltas em uma cortina de fumaça. No que diz respeito à integração massiva da população negra e da redução das disparidades sociorraciais, a mudança simples da gestão da economia, ainda que necessária, é insuficiente. A solução não se reduz à intervenção do Estado, conforme se comportou o Estado brasileiro até a chamada Era Collor. Também não basta produzir o Estado mínimo, como desejam os neoliberais.

Para Vargas (2010, p.41), as desigualdades estruturais e históricas não são confrontadas e combatidas fortemente; o sistema racial de hierarquias continua estabilizado. Para o autor, o que está em jogo vai além do reconhecimento formal de direitos e acesso a recursos:

Tão urgente quanto é esta batalha pragmática do presente, a guerra mais ampla a combater é a que trata do reconhecimento pleno e garantido da humanidade do povo negro. Na verdade é uma guerra por sobrevivência".

\section{Considerações finais}

O processo de domesticação exige que o racismo seja naturalizado e a discriminação racial e de gênero legitimadas, com base em uma lógica conservadora e hierárquica. Na medida em que, culturalmente, a sociedade brasileira e o Estado não romperem com os preconceitos e os estereótipos cristalizados na memória coletiva, nem tampouco criarem uma política de desenvolvimento redistributiva, o Brasil não estará socialmente preparado para experimentar, efetivamente, a democracia em sua plenitude.

Em uma sociedade "racializada" e fortemente marcada pela tradição colonial, o racismo opera, dentre outras formas, para destituir sua vítima da condição humana. Esse exercício diário transforma as pessoas em seres incapazes de reconhecer a dor do outro. O negro é inferior pela sua condição de ex-escravo, cabendo-lhe as migalhas do produto do trabalho, embora tenha, por mais de 300 anos, trabalhado forçadamente sem receber nada por isso. Assim operou a ideologia dominante na colonização, que ainda está presente no imaginário social.

Para o historiador Caio Prado Jr (apud SANTOS, 2009), a identidade nacional é marcada pelo sistema colonial e escravista, em cuja sociedade desenvolveu-se o sistema patriarcal e escravocrata. 


\section{ReVistg all paUtg}

\} DESUMANIZAÇÃO DA POPULAÇÃO NEGRA - ALMEIRA, M. S. \}

Trazendo novamente as ideias de para o debate, Rocha (2013) analisa a lógica do racismo pela dinâmica de dominação, hoje globalizada, responsável pelo genocídio de um número significativo de seres humanos. A humanidade deles não é, então, reconhecida por haver o pensamento de que fora subtraída sua capacidade de pensar, propor e sublevar, pois nem tudo que é sólido desmancha no ar.

Para Moura (apud ROCHA, 2014, p. 23)

o racismo, o mito de superioridade racial de um povo sobre o outro, encobre os interesses de povos que se julgam 'eleitos' e desejam conseguir hegemonia econômica, social e cultural sobre os povos considerados mais fracos. Esta racionalização do preconceito através do racismo exerce papel e função de importância em diversos blocos de poder de nações que disputam a hegemonia no mundo capitalista

Ainda corroborando com a ideia de Diáspora Negra como genocídio, o projeto capitalista, ao "racializar" a população negra, produz simbolicamente noções de inferioridade nas quais raça e cultura são indissociáveis, criando barreiras para a mobilidade social. O eurocentrismo, neste caso, funcionaria como estratégia para impedir o deslocamento social do grupo subjugado, ou seja, a priori define-se o "lugar social" do negro.

Assim, Rocha (2014) dialoga mais uma vez com Moura (1990, p. 215-216), que nos sinaliza que

o etnocentrismo do branco em relação ao negro e ao não-branco em geral teve e tem como função exatamente estabelecer fronteiras hierárquicas do ponto de vista étnico para que os grupos considerados inferiores não pudessem transpô-las através da mobilidade social. Fecha-se, assim, o leque de oportunidades para os membros considerados inferiores. Ressalta ainda, que isto aconteceu desde o Brasil colônia e durante todo o período imperial, prosseguindo, com modificações modernizadoras, até os nossos dias.

Por essas razões, uma práxis comprometida com a emancipação humana deve, sobretudo, tratar o racismo na perspectiva de totalidade social, segundo a experiência concreta da população negra na Diáspora Negra. Não se trata de um imperativo ético-político, tampouco preponderante. No entanto, reivindicamos igualmente o método dialético de análise como mediação fundamental da funcionalidade do racismo na sociabilidade burguesa, a partir de uma práxis negra.

Trata-se de recuperar os abusos e violações sofridas pela população negra, os processos genocidas que fazem parte de suas vidas e que interrompem seus objetivos. Principalmente, trata-se de interrogar suas naturalizadas subordinações de gênero, raça, identidade de gênero e orientação 


\section{Revista pll paעtg}

\} DESUMANIZAÇÃO DA POPULAÇÃO NEGRA - ALMEIRA, M. S. \}

sexual, assim como a análise dessas contradições, para avistar importantes hiperativos para suprimir o genocídio.

A luta de classes não pode prescindir das lutas contra as opressões, que lhes dão vida. 


\section{AeVistg all paUtg}

\} DESUMANIZAÇÃO DA POPULAÇÃO NEGRA - ALMEIRA, M. S. \}

\section{Referências}

ALMEIDA, M.S. Mulher negra militante: trajetórias de vida, identidade e resistência no contexto da política de ações afirmativas na Universidade do Estado do Rio de Janeiro. Tese (Doutorado). Programa de Pós-Graduação em Serviço Social da PUC, Rio de Janeiro. 2011-1

ALVES, J. À ordem branca! O que os ataques do PCC nos têm a dizer? João de Barro, jun. 2006. Disponível em: <http://www.apcefrs.org.br/upload/ paper/jbjun_02_jbjun_12.pdf>. Acesso em: 6 nov. 2014.

DAVIS, A. R. Angela Davis: 'racismo de hoje é mais perigoso'. Pragmatismo Político. Muito. 09 abr. 2013. Entrevista. Disponível em: <http://www. pragmatismopolitico.com.br/2013/04/angela-davis-racismo-de-hoje-emais-perigoso.html>. Acesso em: 30 out. 2014.

DUSSEL, E. 1492: o encobrimento do outro. A origem do mito da modernidade. Petrópolis/Rio de Janeiro: Vozes. 1993.

FLORENTINO, M. Portugal e a escravatura dos africanos. Análise Social, n. 185. 2007. Disponível em: <http://www.scielo.gpeari.mctes.pt/pdf/aso/ n185/n185a12.pdf>. Acesso em: 6 nov. 2014

GONZALEZ, L. Racismo e sexismo na cultura brasileira. Revista Ciências Sociais Hoje, ANPOCS, 1984, p. 223-244. Disponível em: <http://disciplinas.st oa.usp.br/pluginfile.php/247561/mod_resource/content/1/RACISMO\%20E\%20S EXISMO\%20NA\%20CULTURA\%20BRASILEIRA.pdf>. Acesso em: 29 jan. 2015.

GORENDER, J. O épico e o trágico na história do Haiti. Estudos Avançados, v. 18, n. 50, 2004. Disponível em: <http://www.scielo.br/pdf/ea/v18n50/ a25v1850.pdf>. Acesso em: 26 out. 2014.

HASENBALG, C. A. Discriminação e desigualdades raciais no Brasil. Rio de Janeiro: Edições Graal. 1979.

HASENBALG, C.A; SILVA, N.V. (Org.) Estrutura social, mobilidade e raça. São Paulo: Vértice/Editora Revista dos Tribunais; Rio de Janeiro: Instituto Universitário de Pesquisas do Rio de Janeiro. 1988.

HENRIQUES, R. Desigualdade racial no Brasil: evolução das condições de vida na década de 90. Rio de Janeiro: Ipea. 2001.

KONRAD, D.A. Dez anos sem Clóvis Moura - na senzala a resistência, no quilombo a liberdade: a obra de Clóvis Moura. In: SANTOS, J.R.Q; DUTRA, M.R.P. (Org.). Nas trilhas da negritude: consciência e afirmação. Porto Alegre: Martins Livreiro, 2007. p. 115-133.

MARINHO, A. Porta terra: negros e mulheres têm menos acesso a cirurgias, aponta Ipea. IPEA Imprensa, Brasília, 8 jul. 2011. Entrevista concedida no site do IPEA. Disponível em: <http://www.ipea.gov.br/portal/index.php?option=com_con tent\&view=article\&id=9263: porta-terra-negros-e-mulheres-tem-menos-acesso-acirurgias-aponta-ipea\&catid=159:clipping \&ltemid=75>. Acesso em: 29 jan. 2015. 


\section{Revistg all paUtg}

MARINHO, A.; CARDOSO, S.S.; ALMEIDA. V.V. Desigualdade de transplantes de órgãos no Brasil: análise do perfil dos receptores por sexo, raça ou cor. Texto para discussão. Brasília: DF, IPEA, 1629, 2011. 40 p.

MOURA, C. Anti-Pilatos. In: Manequins corcundas. 1977.

. As injustiças de Clio: o negro na historiografia brasileira. Belo Horizonte - Oficina de Livros, 1990.

- Dialética radical do Brasil negro. São Paulo: Anita, 1994.

PESSOA, T.C. O comércio negreiro na clandestinidade: as fazendas de recepção de africanos da família Souza Breves e seus cativos. Afro-Ásia, n. 47. 2013. Disponível em: <http://www.afroasia.ufba.br/pdf/AA_47_TC Pessoa.pdf >. Acesso em: 10 nov. 2014.

PAIXÃO, M. Desenvolvimento humano e relações raciais. Rio de Janeiro: DP\&A, 2003. [Coleção Políticas da Cor].

PAIXÃO, M. et al. (Org.). Relatório anual das desigualdades raciais. 20092010. Constituição Cidadã, seguridade social e seus efeitos sobre as assimetrias de cor ou raça. Rio de Janeiro: Garamond. 2010. Disponível em: <http://www.laeser.ie.ufrj.br/PT/relatorios\%20pdf/Relat\%C3\%B3rio_20092010.pdf>. Acesso em: 26 out. 2014.

PRANDI, R. De africano a afro- brasileiro: etnia, identidade e religião. Revista Usp, São Paulo, n.46, p. 52-65, jun./ago. 2000

RATTS, A. Eu sou atlântica: sobre a trajetória de vida de Beatriz Nascimento. São Paulo: Imprensa Oficial do Estado de São Paulo / Instituto Kuanza. 2007. RETRATO das desigualdades de gênero e raça / Instituto de Pesquisa Econômica Aplicada ... [et al.]. - 4aㅡ ed. - Brasília: Ipea, 2011. 39 p.

ROCHA, F.R. A incorporação da temática étnico-racial no processo de formação em serviço social: avanços e desafios. Tese (Doutorado) - Programa de Pós-Graduação em Serviço Social. Escola de Serviço Social da UFRJ. 2014. Mimeo.

SANTOS, G. Relações raciais e desigualdades no Brasil. São Paulo: Selo Negro, 2009. Consciência e Debate.

WAISELFISZ, J.J. Mapa da violência 2011: os jovens no Brasil, São Paulo. Instituto Sangari. Brasília, DF: Ministério da Justiça, 2011. 161 p.

. Mapa da violência 2013: homicídios e juventude no Brasil. Brasília: Secretaria-Geral da Presidência da República, 2013. 98 p.

VARGAS, J. C. A diáspora negra como genocídio: Brasil, Estados Unidos ou uma geografia supranacional da morte e suas alternativas. Revista da ABPN, v. 1, n. 2, jul./out. 2010. Disponível em: < http://www.abpn.org.br/Revista/ index.php/edicoes/article/view/90>. Acesso em: 10 nov. 2014.

Recebido em 18 de novembro de 2014.

Aprovado para publicação em 08 de dezembro de 2014. 